\title{
Pacific multidecadal ( $50-70$ year) variability instigated by volcanic forcing during the Little Ice Age (1250-1850)
}

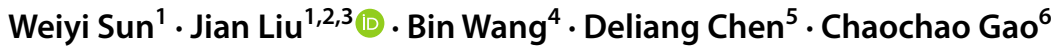

Received: 18 August 2021 / Accepted: 28 December 2021 / Published online: 13 January 2022

(c) The Author(s) 2022

\begin{abstract}
The Pacific decadal oscillation (PDO) is the leading mode of decadal climate variability over the North Pacific. However, it remains unknown to what extent external forcings can influence the PDO's periodicity and magnitude over the past 2000 years. We show that the paleo-assimilation products (LMR) and proxy data suggest a 20-40 year PDO occurred during both the Mediaeval Climate Anomaly (MCA, 750-1150) and Little Ice Age (LIA, 1250-1850) while a salient 50-70 year variance peak emerged during the LIA. These results are reproduced well by the CESM simulations in the all-forcing (AF) and single volcanic forcing ( Vol) experiments. We show that the 20-40 year PDO is an intrinsic mode caused by internal variability but the 50-70 year PDO during the LIA is a forced mode primarily shaped by volcanic forcing. The intrinsic mode develops in tandem with tropical ENSO-like anomalies, while the forced mode develops from the western Pacific and unrelated to tropical sea surface temperature anomalies. The volcanism-induced land-sea thermal contrast may trigger anomalous northerlies over the western North Pacific (WNP), leading to reduced northward heat transport and the cooling in the Kuroshio-Oyashio Extension (KOE), generating the forced mode. A 50-70 year Atlantic multidecadal oscillation founded during the LIA under volcanic forcing may also contribute to the forced mode. These findings shed light on the interplay between the internal variability and external forcing and the present and future changes of the PDO.
\end{abstract}

Keywords PDO $\cdot 50-70$ year variability $\cdot$ Little Ice Age $\cdot$ Volcanic forcing $\cdot$ CESM $\cdot$ Past 2000 years

Jian Liu

jliu@njnu.edu.cn

1 Key Laboratory for Virtual Geographic Environment, Ministry of Education, State Key Laboratory Cultivation Base of Geographical Environment Evolution of Jiangsu Province Jiangsu Center for Collaborative Innovation in Geographical Information Resource Development and Application, School of Geography Science, Nanjing Normal University, Nanjing 210023, China

2 Jiangsu Provincial Key Laboratory for Numerical Simulation of Large Scale Complex Systems, School of Mathematical Science, Nanjing Normal University, Nanjing 210023, China

3 Open Studio for the Simulation of Ocean-Climate-Isotope, Qingdao National Laboratory for Marine Science and Technology, Qingdao 266237, China

4 Department of Atmospheric Sciences and Atmosphere-Ocean Research Center, University of Hawaii at Manoa, Honolulu, HI 96825, USA

5 Regional Climate Group, Department of Earth Sciences, University of Gothenburg, 40530 Gothenburg, Sweden

6 College of Environmental and Resource Science, Zhejiang University, Hangzhou 310058, China

\section{Introduction}

The Pacific decadal oscillation (PDO) is the leading empirical orthogonal function (EOF) mode of the North Pacific sea surface temperature (SST) variability (Mantua et al. 1997). It has a profound climate impact on the Eurasian, North American, and North Pacific ecosystems and fisheries (Liu and Di Lorenzo 2018; Newman et al. 2016).

Previous studies have linked the PDO with various climatic dynamic processes (Newman et al. 2016). The remote tropical forcing is considered one of the drivers (Deser et al. 2004). The El Niño-Southern Oscillation (ENSO)-related SST pattern was found to affect the Aleutian Low variability through the atmospheric bridge (Alexander 1992, 2010) and seasonal footprinting (Vimont et al. 2001; Deser et al. 2012), contributing to a PDO-like pattern on both interannual and decadal time scales. The tropical Pacific pacemaker experiment demonstrated that the tropical SST-forced PDO component resembles the internal mode in the Northern Hemisphere but differs in the Southern Hemisphere (Zhang et al. 2018). Mid-latitude atmosphere-ocean interaction can also 
contribute to the PDO. Using the Geophysical Fluid Dynamics Laboratory (GFDL) model, some studies found that the bi- and multi-decadal PDO mode can be affected by air-sea interactions via the westward propagating oceanic Rossby waves (Zhong et al. 2008; Zhong and Liu 2009; Zhang and Delworth 2015). The importance of air-sea interactions was stressed in the Kuroshio-Oyashio Extension (KOE) region (Taguchi et al. 2007; Liu and Lorenzo 2018). The atmospheric circulation change over the subtropical gyre can influence poleward transport of warm water along the western boundary and the KOE pathway, changing the meridional SST gradients and the Aleutian low system over the North Pacific (Latif and Barnett 1994). The PDO was also shown to exist due to air-sea thermodynamic feedback without invoking ocean dynamics (Kwon and Deser 2007). These mechanisms essentially treat the PDO as an internal mode of variability, while little has been known whether and how the external forcing can force the PDO-like variations.

The future change of the PDO under anthropogenic forcing, including the periodicity, amplitude, and mechanism, remains controversial. The Intergovernmental Panel on Climate Change (IPCC) Fifth Assessment Report (AR5) concluded that the near-term predictions of the PDO were uncertain and model-dependent (IPCC 2013). Some studies projected increased variances of the PDO and tropical decadal variability in a warmer climate using the Community Earth System Model Large Ensemble (CESM-LE) (Di Lorenzo and Mantua 2016; Liguori and Di Lorenzo 2018). These changes in Pacific decadal variability could be related to the increased Pacific Meridional Mode variance, influenced by enhanced wind-evaporation-SST feedback or stochastic atmospheric variability (Liguori and Di Lorenzo 2018). However, some other Coupled Model Intercomparison Project 5 (CMIP5) models suggested a reduced magnitude of the PDO under greenhouse warming. It is consistent with the shortened PDO periodicity and duration due to the accelerated westward propagation of oceanic Rossby waves caused by enhanced ocean stratification (Zhang and Delworth 2016; Geng et al. 2019; Li et al. 2020).

Understanding how natural external forcing may influence the PDO can provide valuable insight into the causes of the past climate variability and PDO's response to the current climate change. However, existing studies have focused on the impact of anthropogenic forcings on PDO change and paid little attention to natural external forcings, such as volcanic eruptions and solar radiation. In addition, instrumental observations are too short to provide reliable data to understand how the PDO responds to different external forcings.

The past two millennia can be the prime time to address the issue mentioned above. Using tree-ring data from California and Alberta, MacDonald and Case (2005) produced a PDO index during the period of 993-1996. They found a significant $50-100$ year oscillation during the fourteenth-sixteenth centuries, while it was absent from the seventeenth to nineteenth centuries. Their reconstructed PDO index was found to be negatively correlated with the reconstruction made by D'Arrigo and Wilson (2006) on the multidecadal (about 50 year) time scale (Fang et al. 2019). Using many reconstructions, Fang et al. (2019) proposed that the PDO has displayed persistent multidecadal (50-100 year) variability during the Little Ice Age (LIA, 1250-1850). The study also found significant correlations between the PDO indices reconstructed by Biondi et al. (2001) and MacDonald and Case (2005) on the multidecadal time scales (50-70 year). Nevertheless, inconsistencies exist among different reconstructions. The underlying mechanisms behind the PDO change remain unknown.

Paleoclimate modeling makes it possible to carry out sensitivity simulations to identify the roles of individual physical processes and better comprehend complex physical processes. Using the last 600 years Bergen Climate Model simulation, Wang et al. (2012) found that large tropical volcanoes and solar forcing can regulate the PDO. A negative phase of the PDO occurs several years after tropical eruptions through troposphere-stratosphere coupling and tropical-extratropical teleconnections. Jin et al. (2019) showed that a PDO-like SST pattern might be excited by solar forcing by analyzing the simulation with the CESM-Last Millennium Ensemble (CESM-LME), but they focused on the 11-year solar cycle, and the specific processes controlling the SST pattern were unclear. On the contrary, Ratna et al. (2019) analyzed the simulations from seven Paleoclimate Model Intercomparison Project 3 (PMIP3) climate models. They could not find any significant correlation between the PDO and solar-volcano forcings during the last millennium. Besides, a negative correlation between PDO and Atlantic multidecadal oscillation (AMO) was found to have strengthened from mid-seventeenth to twentieth centuries in a CESM-LME experiment with land use/cover change (Wang et al. 2021).

In this study, the science questions to be addressed include: (1) How did the PDO characteristics (i.e., periodicity and magnitude) change over the past 2000 years? (2) What caused the change, if any? In particular, how might different external forcings have influenced the North Pacific multidecadal variability?

To better understand the responses of the PDO to different external forcings, we conduct a set of experiments including the control, all-forcing, and four single-forcing experiments during the past 2000 years. We compare the simulation results with the reconstructions and assimilation data. This research investigates the change in periodicity and amplitude of the PDO under different external forcing over the past 2000 years and the underlying physical processes. This paper is organized as follows: In Sect. 2, we describe the CESM simulations, proxy, and assimilation data. In 
Sect. 3, we investigate the change of the PDO under different external forcings over the past 2000 years. Section 4 explains the mechanism by which volcanic forcing could affect the PDO on the multidecadal time scales. In Sect. 5, we discuss and summarize the key findings.

\section{Data and methods}

\subsection{Experimental design}

In this study, we used the CESM1 (Hurrell et al. 2013), with a resolution of T31 (horizontal resolution of about $\left.3.75^{\circ} \times 3.75^{\circ}\right)$. A control (Ctrl) experiment is conducted under the pre-industrial conditions with a 400 year spinup run and continues to run for 2000 years, which is at the steady state already. Then, five 2000-year transient climate simulation experiments are carried out, starting from the last year of the Ctrl experiment. These include the total solar irradiation (TSI) experiment, volcanic eruption (Vol) experiment, land use/land cover change (LUCC) experiment, greenhouse gases (GHGs) experiment, and all-forcing (AF) experiment (Wang et al. 2015; Sun et al. 2017). One of the reasons for running the entire Common Era is to understand the change of climate in a longer time; Second, it provides the initial conditions for the climate simulations over the past millennium, which is traditionally neglected in the PMIP past 1000 simulations.

The amplitude of TSI forcing used in this study is reconstructed by Shapiro et al. (2011) and is larger than some other solar irradiation reconstructions used in the past 1000 simulations in the PMIP4 (Jungclaus et al., 2017), but is useful to test the climate sensitivity of solar forcing. However, the orbital forcing is fixed and same as that of Ctrl run in this study. For the LUCC forcing, since the time length of LUCC forcing used by PMIP4 is limited to 850-2015 (Jungclaus et al., 2017), we use the reconstructed results over the past 2000 years provided by Kaplan et al. (2010), which has been processed via a one-to-one mapping method shown to be suitable for driving the CESM (Yan et al. 2017). Following the designs of PMIP and CESM-LME (Schmidt et al. 2011; Otto-Bliesner et al. 2016), we use the GHGs forcing reconstructed by MacFarling et al. (2006).

The volcanic forcing used in the last millennium simulations of PMIP3 and CESM-LME is derived from the Ice-core Volcanic Index 2 (IVI2) (Gao et al. 2008), which provides records of volcanic eruptions during the past 1500 years and information about the monthly mean spatial-temporal distribution of volcanic aerosols. Sigl et al. (2015) reconstructed the time series of volcanic eruptions over the past 2500 years, but this record cannot be directly used to force the climate experiment. Therefore, in this study, the volcanoes during the period of 1-500 from Sigl et al. (2015) are extended in time and space using the same parameterization method as IVI2 and then integrated with IVI2 (Gao et al. 2008). The volcanic forcing developed by Toohey and Sigl (2017) is recommended for the PMIP4 past 1000 simulations, which is based on the Sigl et al. (2015) dataset processed by the Easy Volcanic Aerosol (EVA). Previous studies have found that the influence of IVI2 forcing on the ENSO, monsoon precipitation, and Arctic climate simulated by CESM are reasonable and correspond well to observations and proxy data (Liu et al. 2016, 2020; Sun et al. 2019a, b).

\subsection{Observational data}

Two sets of SST observational data from 1870 to 2000 are used to evaluate the simulation performance. The first is the Extended Reconstructed Sea Surface Temperature, version 5 (ERSST v5) global SST monthly data on a $2^{\circ} \times 2^{\circ}$ horizontal grid from January 1854 to the present (Huang et al. 2017). The second one is the Hadley Center Sea Ice and SST dataset version 1.1 (HadiSST 1.1) with a $1^{\circ} \times 1^{\circ}$ resolution from 1871 to the present (Rayner et al. 2003).

\subsection{Assimilation and reconstruction}

To show the PDO change over the past two millennia, we use the annual mean SST and the PDO reconstruction derived from the Last Millennium Reanalysis (LMR) v2.0 (Fig. S1), which is based on a combination of climate model simulations and reconstructed data with the data assimilation methodologies. The detailed information can be obtained from Tardif et al. (2019). The ability of LMR in estimating the temperature and hydroclimate response to external forcings has been verified in previous studies (i.e., Tejedor et al. 2021).

The PDO index reconstruction we used here is based on the tree-ring data from California and Alberta for 993-1996 (MacDonald and Case 2005). Other PDO reconstructions are too short to cover at least the last millennium. Correlation coefficient between the 9-year low-pass filtered reconstructed PDO indices derived from the LMR and the work of MacDonald and Case (2005) is about $0.30(p<0.01)$ during the 993-1996, which is significant after considering the effective degrees of freedom ( $n=221$ after low-pass filter during 993-1996). However, the correlation coefficient of 0.3 is low and there are large differences between these two data, which may be caused by some uncertainties in each data. 


\section{Secular change of PDO during the past 2000 years}

\subsection{Observed and simulated PDO during 1871- 2000}

Following Mantua et al. (1997), the PDO in this study is defined by the EOF1 of 9-year low-pass filtered annual mean SST anomalies over the North Pacific (north of $20^{\circ} \mathrm{N}$ ). The PDO index is represented by the corresponding principal component (PC1). Figure 1 compares the PDO patterns and power spectra of the PDO index derived from the observations (ERSST and HadiSST), LMR and simulated data from the AF experiment during 1871-2000. The observed patterns in the HadiSST display a horseshoelike pattern, but the central North Pacific cooling center is more eastward and there is no warm SST over the North American coast in the ERSST. The power spectral peak is at 25-30 years in ERSST and 20 years in HadiSST, suggesting observational uncertainties. The PDO's pattern in the LMR and AF experiment resemble the two observed counterparts, but the cooling center shifted westward by about 10 degrees of longitude, and the coastal eastern North Pacific shows excessive warming (Fig. 1e). The associated PC1s display significant peaks on 20 and 25 years in the LMR and AF experiment, respectively, which is roughly consistent with the observed 20-30 year peak. Thus, both LMR and AF run reproduce reasonably realistic spatial pattern and periodicity of the North Pacific decadal variability from 1871 to 2000 .

\subsection{The PDO's intrinsic mode and forced mode}

We performed wavelet analysis of the PDO index to detect PDO's periodicity and magnitude changes over the past 2000 years. Figure $2 \mathrm{a}$ shows the result from the assimilated proxy dataset, i.e., the SST derived from the LMR. The lack of variability during 100-600 AD, to our best knowledge, is probably due to the absence of PDO reconstruction. During the Mediaeval Climate Anomaly (MCA, 750-1150), the major periodicities of the PDO are found on 30-40 year time scales, which is confirmed by the power spectral analysis result (Fig. 3a). During the LIA, the PDO displays prominent variance on the $50-70$ year band, verified by the conspicuous
Fig. 1 Evaluation of the model's performance in capturing the PDO. a The EOF1 pattern of SST over the North Pacific during 1871-2000 and b the power spectral analysis of SST PC1 derived from the ERSST after applying a 9-year low-pass filter. $\mathbf{c}-\mathbf{h}$ are the same as in $\mathbf{a}, \mathbf{b}$, but derived from the HadiSST, LMR, and AF experiment, respectively. The dashed lines in $\mathbf{b}, \mathbf{d}, \mathbf{f}$, and $\mathbf{h}$ represent the $90 \%$ and $95 \%$ confidence level
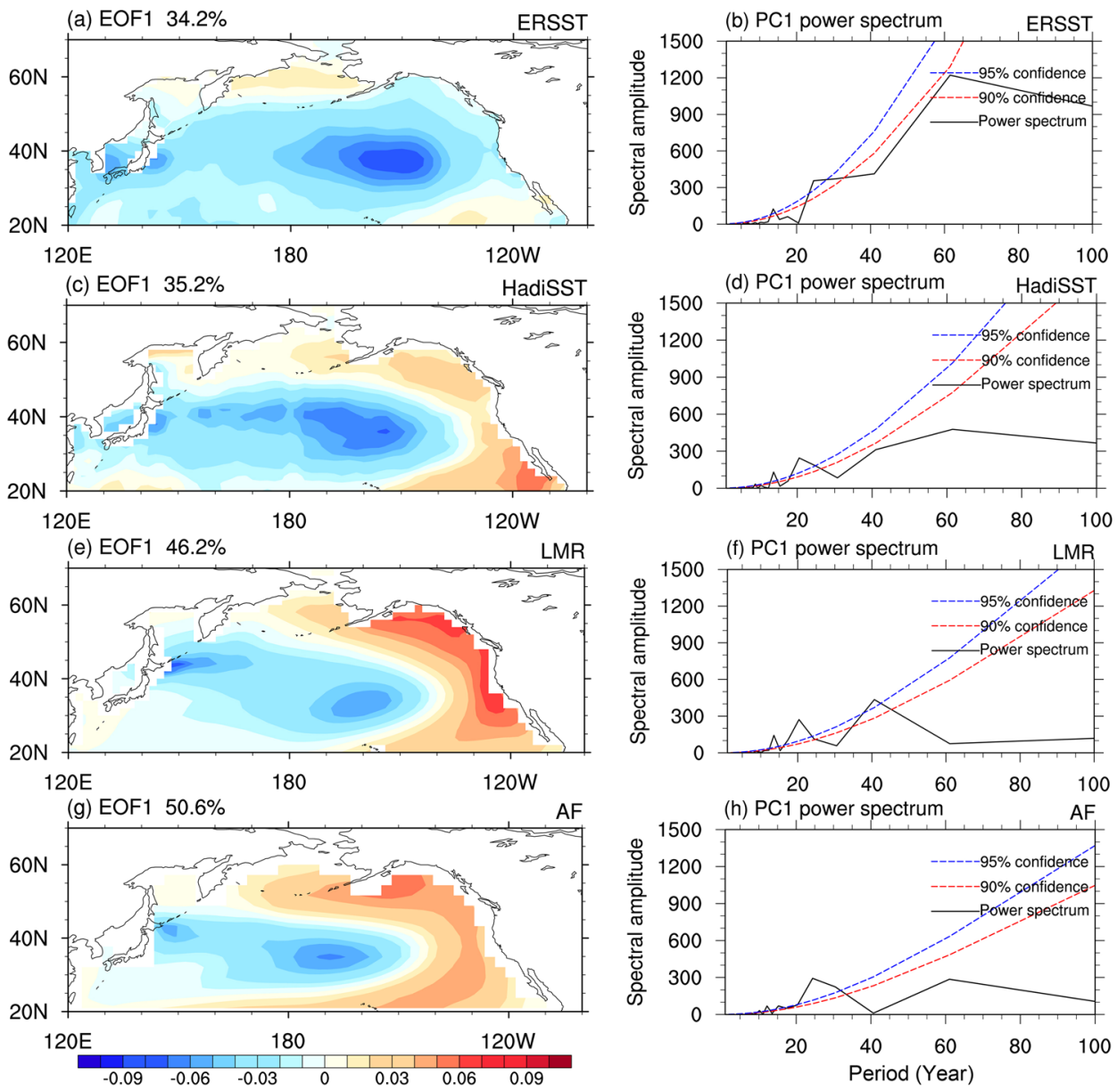


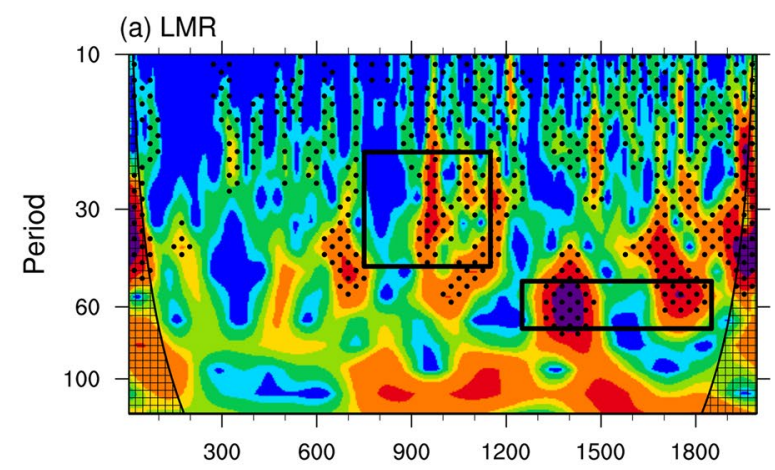

(c) Vol

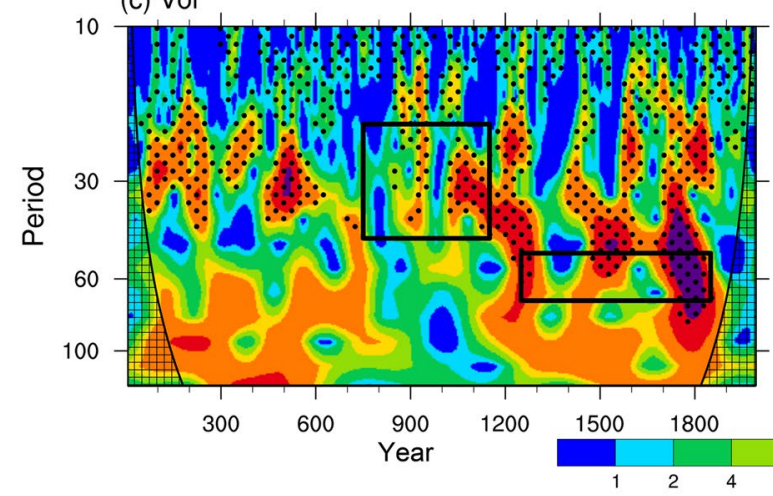

(b) AF

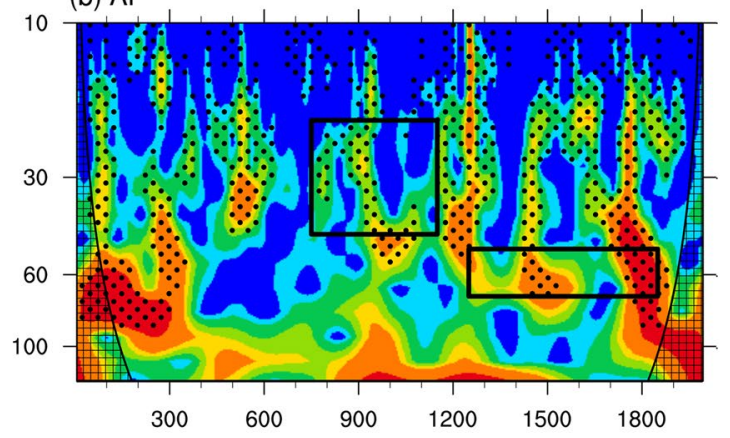

(d) TSI

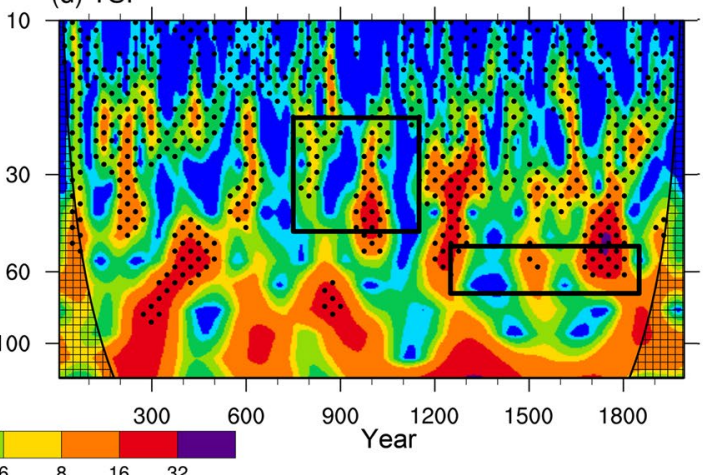

Fig. 2 Changes of the PDO index over the past 2000 years as revealed by wavelet analyses of the PDO index in the Last Millennium Reanalysis (LMR) v2.0 (a), AF (b), Vol (c), and TSI (d) experi- ments. The black dots denote significance at the $90 \%$ confidence level. The black boxes outline the $20-45$ yr cycle during the MCA and the 50-70 years cycle during the LIA, respectively peak around 60 years (Fig. 3b). Meanwhile, the 20-40 year variability remains active, and the corresponding spectral peak is significant. Similar cycle change is found in both the SST and PDO reconstruction derived from LMR v2.1 and v2.0 (Fig. S2). The reconstruction by MacDonald and Case (2005) suggests a 30 year peak occurs during the MCA while the 20-30 year and multidecadal peaks (43 year and 55 year peaks) are significant during the LIA (Fig. 3c, d).

What happened in the Ctrl and AF simulation? In the Ctrl simulation, the PDO has significant 20 year and 40 year power spectral peaks (Fig. 3g), suggesting that the model's internal variability produced PDO has an intrinsic 20-40 year periodicity, which can be called "intrinsic mode". On the other hand, in the AF experiment, the PDO periodicities have experienced noticeable changes. During the MCA, the 20-25 year variation dominates, with a marginally significant 40 year variability (Figs. 2b, 3e). In contrast, during the LIA, a salient low-frequency (60 year) peak emerged under the external forcings in addition to the 20 year and 40 year peaks (Fig. 3f), which can be referred to "forced mode". These features bear some resemblance with those seen in the LMR and reconstruction (MacDonald and Case 2005) (Fig. 3a-d). The results derived from the Ctrl and AF simulations suggest that the $20-40$ year mode due to the internal variability exists in both the MCA and LIA or throughout the past 2000 years, but a new 60 year variation mode emerged during the LIA under the external forcing. Hereafter we refer to the $20-40$ year mode as intrinsic mode and the 50-70 year mode as forced mode.

To find out the origin of the emerging 50-70 year mode during the LIA, we further examined single-forcing simulations' results. We find that the Vol and TSI forced simulations produce wavelet spectra similar to the AF run (Fig. 2c, d). In the Vol experiment, the 30-35 year variation prevails during the MCA, but 50-70 year variation predominates during the LIA (Fig. 3i), which is largely consistent with the AF experiment and LMR. During the LIA, volcanic eruptions were stronger and more frequent than the MCA (Gao et al. 2008; Sigl et al. 2015), which may induce a pronounced 60 year spectral peak of volcanic forcing during the LIA but not in the MCA (Figs. S3a, b). The TSI forcing shows the significant multidecadal variability during both the MCA and LIA (Figs. S3c, d), but the TSI experiment shows that the multidecadal periodicity of PDO only occurs during the LIA (Fig. 3j, k), which suggests that there are some uncertainties in the forced mode under the effect of TSI. In the GHGs and LUCC experiments, the PDO's spectra only show significant peaks on a $20-40$ year time scale 

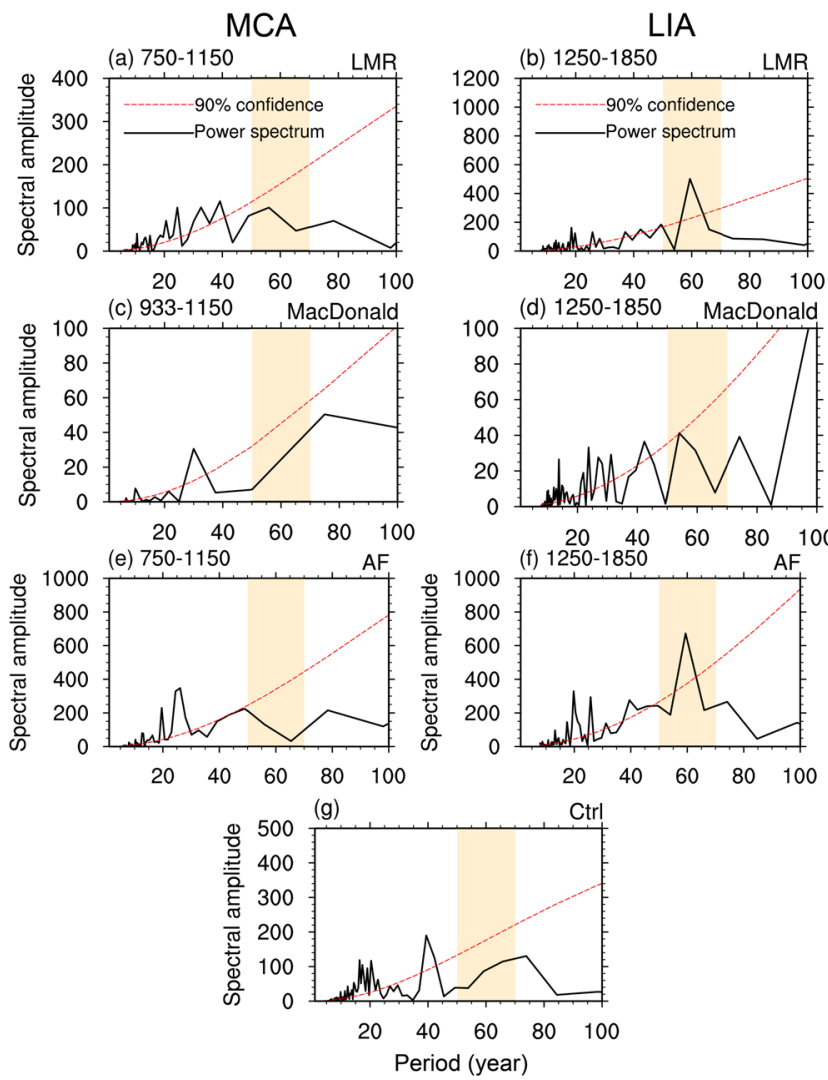

Fig. 3 The power spectral analysis of the PDO index derived from the LMR assimilation (a, b), MacDonald and Case (2005) reconstructed data (c, $\mathbf{d})$, and model-simulated data (e-o) during the MCA and LIA. e, f Show the results in the AF experiment. g Represents the PDO index in the last 600 years in the Ctrl experiment. $(\mathbf{h}, \mathbf{i}),(\mathbf{j}$,

but no significant 60 year peak (Fig. 31-0). The spectral analysis results suggest that the 60 year North Pacific variability that emerged during the LIA in the AF run likely arises from the volcanic and solar irradiance forcings.

\subsection{Change in the amplitudes of intrinsic and forced modes}

Since the PDO intrinsic mode is mainly on the $20-40$ year time scale and the forced mode is on the 50-70 year time scale, we use the 15-45 year band-pass and 45 year lowpass filters to separate the intrinsic and forced modes. The difference in SST standard deviation (STD) is computed to measure the change in SST variability from MCA to LIA (Fig. 4). The $F$-test is used to detect if the difference is significant. Statistical tests are all based on the effective degrees of freedom (Bretherton et al. 1999).

For the intrinsic mode, the LMR data suggest a significant enhancement in the SST variability over the North Pacific during the LIA, compared with the MCA (Fig. 4a). However, the Vol experiment shows no significant increase
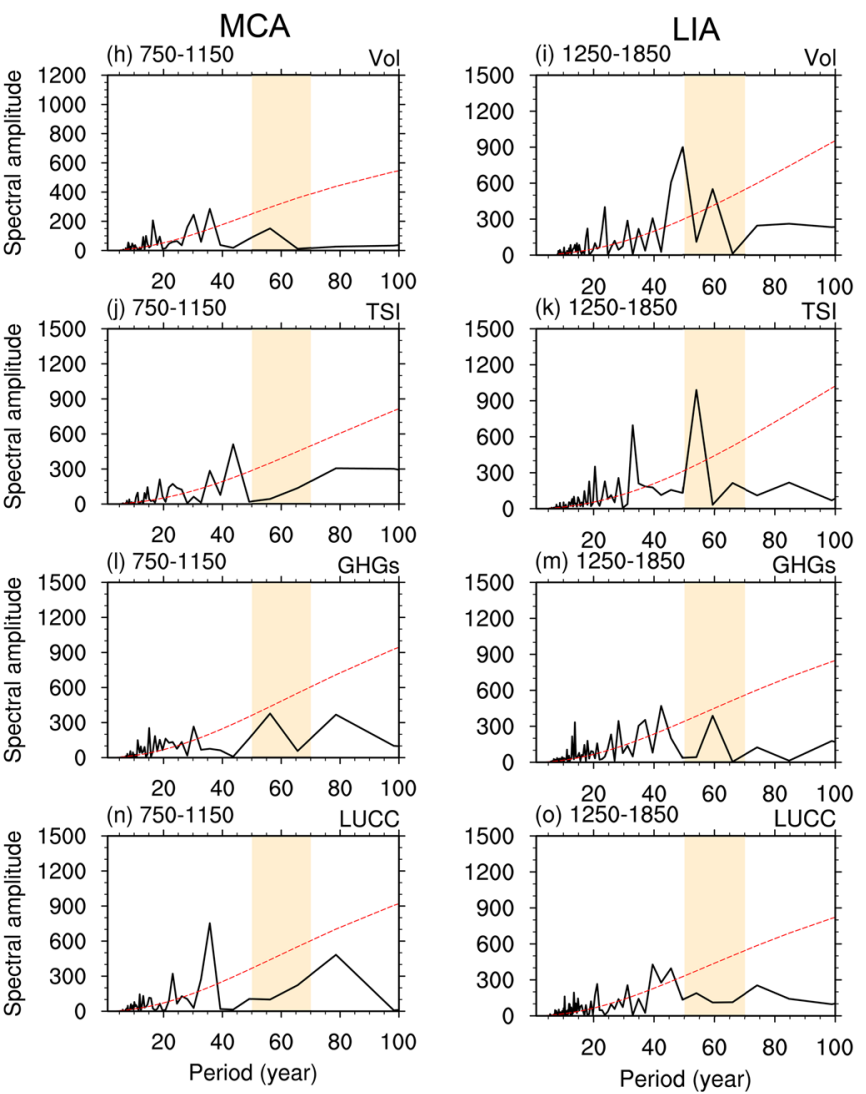

$\mathbf{k}),(\mathbf{l}, \mathbf{m})$, and $(\mathbf{n}, \mathbf{o})$ Show the results from the Vol, TSI, GHGs, and LUCC experiments, respectively. The orange shadings mark the periodicity of 50-70 years. The dashed red line in each panel represents the $90 \%$ confidence level

in SST variability except over the tropical western North Pacific (Fig. 4c). There is nearly no enhanced SST variability over the North Pacific in the TSI, GHGs, and LUCC experiments (Fig. 4e, g, i). The results indicate that the external forcings do not change the amplitude of intrinsic mode, which means that the change in intrinsic mode's amplitude in the LMR is mainly caused by internal variability. Meanwhile, the increased number and quality (i.e., time resolution) of proxy data during the LIA used in the data assimilation might also influence the results (Singh et al. 2018).

There is an increased SST variability for the forced mode over northern and western parts of the North Pacific from MCA to LIA in the LMR (Fig. 4b). In the Vol experiment, a primary maximum intensification occurs in the KOE region, and a secondary maximum center occurs over the tropical eastern North Pacific (Fig. 4d). Under the TSI forcing, the SST variability increases over the central North Pacific and western boundary (Fig. 4f). Additionally, the GHGs and LUCC forcings do not influence the forced mode during the LIA (Fig. 4h, j). Thus, the LMR and the Vol and TSI 
Fig. 4 Differences in the standard deviation (STD) of the intrinsic mode (left) and forced mode (right) between the LIA and MCA derived from LMR (a, b), $\operatorname{Vol}(\mathbf{c}, \mathbf{d})$, TSI $(\mathbf{e}, \mathbf{f})$, GHGs $(\mathbf{g}, \mathbf{h})$, and LUCC $(\mathbf{i}, \mathbf{j})$ experiments. The intrinsic and forced modes are represented by the 15-45 years band-pass filtered and the 45 years low-pass filtered data, respectively. The dots show where the differences in STD are significant at the 90\% confidence level $(F$ test $)$
15-45 yr bandpass

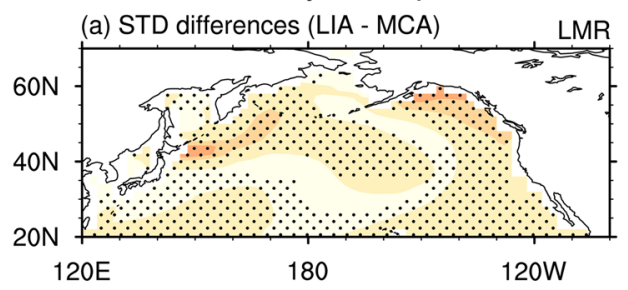

(c) STD differences (LIA - MCA) Vol

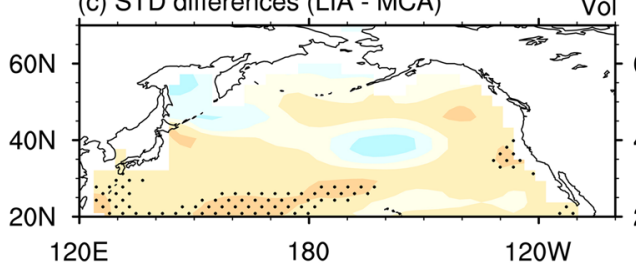

(e) STD differences (LIA - MCA) TSI
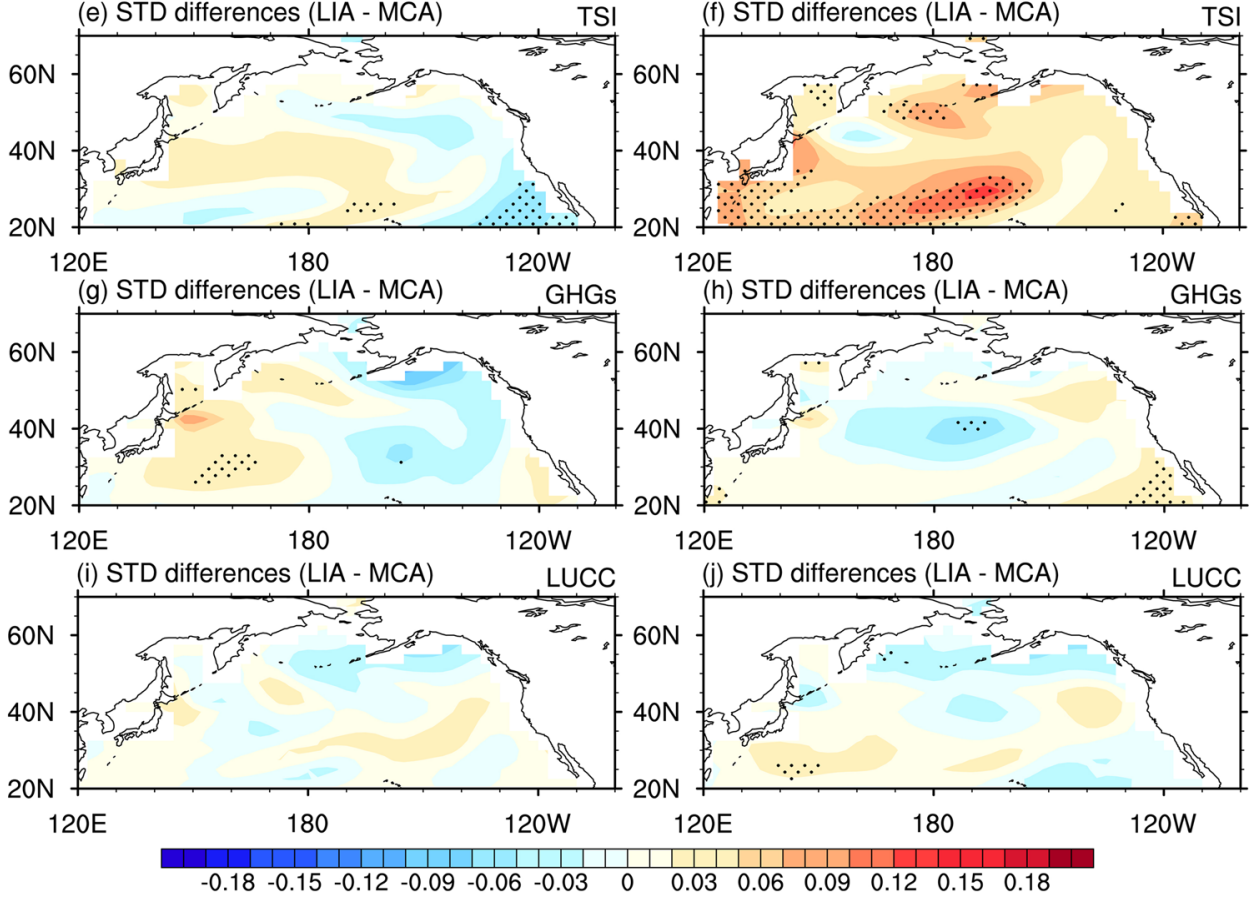

45 yr lowpass
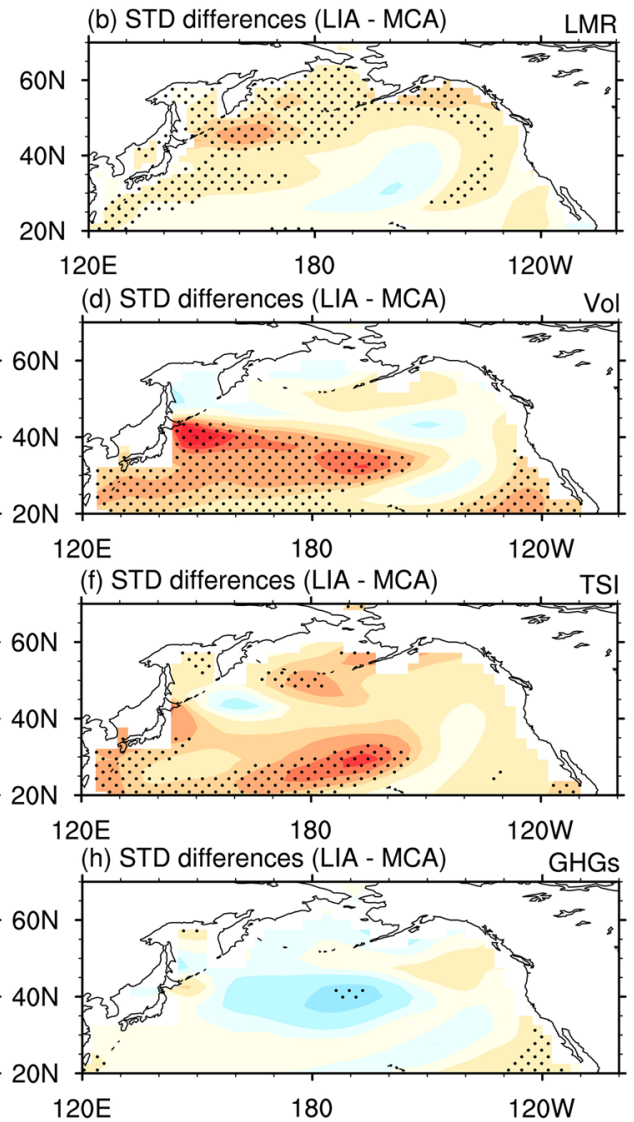

simulations show that the overall North Pacific multidecadal variability is enhanced, but the spatial patterns are different between the LMR and CESM.

The difference in the SST variability change between the Vol and TSI is further examined by comparing the EOF pattern change of the 60 year forced mode (Fig. 5). During the MCA, the EOF1 pattern mainly shows the warm SST over the Northeastern Pacific in the Vol experiment (Fig. 5d), which is not similar to the pattern of PDO. This is because that the PDO index has no significant periodicity greater than 40 years during the MCA (Fig. 3h), and the 45-year low-pass filter largely reduces the PDO-like pattern. To compare the forced mode's amplitudes during the MCA and LIA, the PC1 is normalized and the EOF1 is multiplied by the corresponding singular value in each period. From the MCA to LIA, an enhanced SST amplitude happens over the KOE region under volcanic forcing (Fig. 5f) while a weaker increase occurs in the central North Pacific SST amplitude under TSI forcing (Fig. 5c). The result suggests that the volcano forcing might play a more important role in generating the 60 year forced mode from the MCA to LIA than the TSI forcing. Therefore, in the following section, we will mainly compare the results from the Ctrl and Vol experiments to investigate the underlying mechanisms of the forced mode. The reasons why solar activity mainly affects the changes in the central North Pacific during the LIA are discussed in the discussion section. 
Fig. 5 EOF1 pattern of 45-year low-pass filtered SST during the MCA (a) and LIA (b) in the TSI experiment. The corresponding $\mathrm{PC} 1$ is normalized by its standard deviation. c Differences in the EOF1 pattern of 45-year low-pass filtered SST in the TSI experiment between the LIA and MCA. The PC1 is normalized and the EOF1 is also multiplied by the corresponding singular value in each period, and thus the EOF1 patterns from different periods can be compared. $\mathbf{d}-\mathbf{f}$ are the same as $\mathbf{a}-\mathbf{c}$, but for the results in the Vol experiments
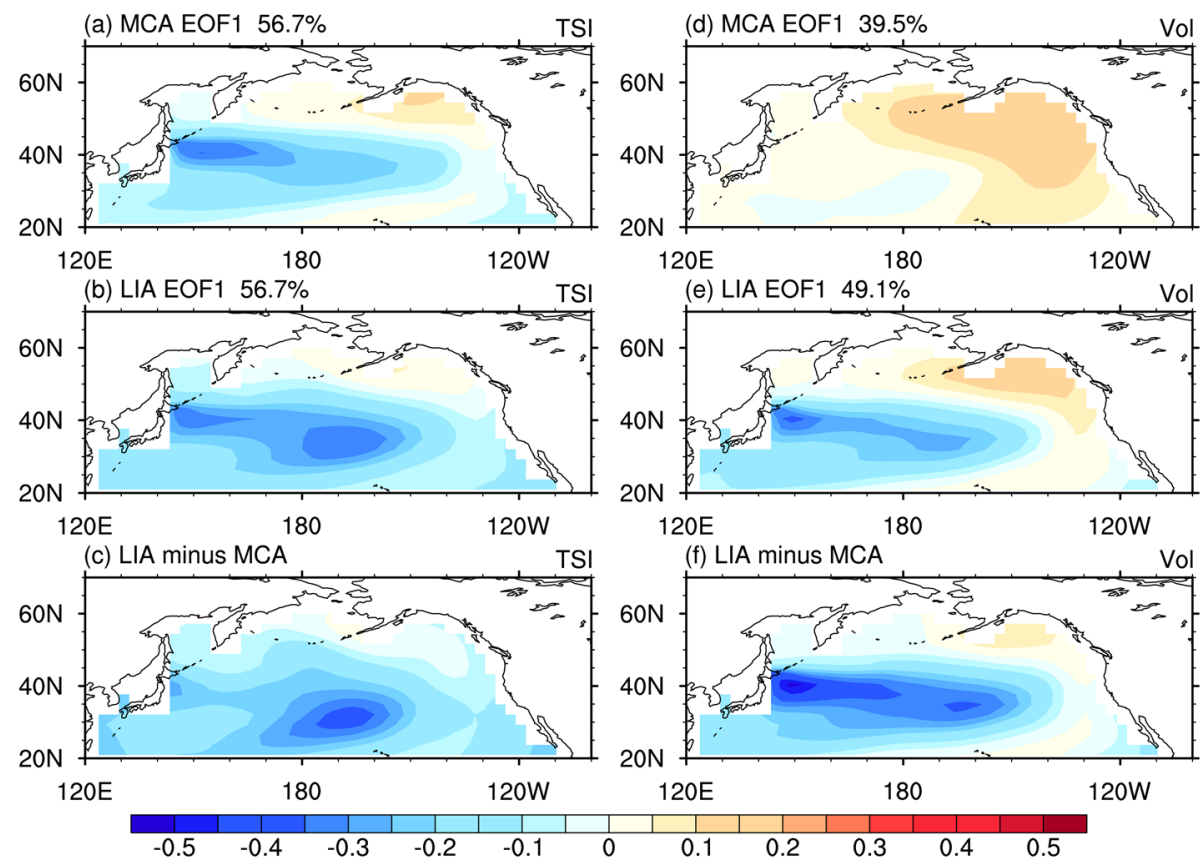

\section{Physical processes responsible for the $\mathbf{6 0}$ year forced mode}

To reveal the dynamic processes of the development of the forced mode, we compared the evolutions of the anomalous SST and $925 \mathrm{hPa}$ winds associated with the indices of the intrinsic mode in the Ctrl run and the forced mode in the Vol run, respectively (Fig. 6). The intrinsic mode index is defined by the normalized PC1 of the EOF1 of the 15-45 year band-pass filtered SST anomalies over the North Pacific (north of $20^{\circ} \mathrm{N}$ ). The definition of volcano-forced mode is the same as the intrinsic mode but using the 45 year low-pass filtered SST anomalies.

In the Ctrl experiment, there is warming over the $\mathrm{KOE}$ region with an anomalous cyclone over the Northeastern Pacific at -6 year (6 years before the peak phase of the intrinsic mode) (Fig. 6a). Then the warming decays, and the anomalous KOE cooling and North Pacific cyclone gradually develop from the lag of 5 to 0 year (Fig. 6, left). For the forced mode, an anomalous cooling starts over the western North Pacific (WNP) region at -18 year (Fig. 6b). It develops from the North Pacific western boundary and expands to the KOE region from -15 to 0 year (Fig. 6, right). The anomalous northerlies occur over the WNP region at -18 year (Fig. $6 \mathrm{~b}$ ), and then they enhance and combine with the anomalous North Pacific cyclone. The anomalous 0-300 m mean ocean temperature shows a similar evolution to the SST change (Fig. S4). It means that the forced mode during the LIA involves both the SST and subsurface temperature. These results suggest that the forced mode begins to develop from the WNP.
Next, we show the chain scenarios over the WNP region $\left(20^{\circ} \mathrm{N}-35^{\circ} \mathrm{N}, 120^{\circ} \mathrm{E}-150^{\circ} \mathrm{E}\right)$ through analyzing the evolution of the SST, meridional surface wind stress, the surface heat flux over the WNP, and the land-sea thermal contrast (LSTC; temperature averaged over $25^{\circ} \mathrm{N}-40^{\circ} \mathrm{N}$, $100^{\circ} \mathrm{E}-120^{\circ} \mathrm{E}$ minus $10^{\circ} \mathrm{N}-20^{\circ} \mathrm{N}, 110^{\circ} \mathrm{E}-140^{\circ} \mathrm{E}$ ) (Fig. 7). For the intrinsic mode, the correlation coefficient between the LSTC and SST over the WNP is not significant, which means that the LSTC does not play an important role in the development of the PDO (Fig. 7a). Unlike the intrinsic mode, the significantly decreased LSTC and anomalous northerly wind stress over the WNP occur around -18 year for the forced mode (Fig. 7b). We calculate the correlation coefficient between the global mean volcanic aerosols and LSTC after a 45 year low-pass filter is about $0.40(p<0.05$, with the effective degrees of freedom around 25), which means that the decreased LSTC is induced by volcanic forcing (Man et al. 2014). After 1-2 year, the cooling develops over the WNP, followed by the loss of downward surface heat flux at -14 year, reducing the local SST. It weakens the northward transport of warm water along the western boundary and the path of KOE, which intensifies the cooling over the KOE and associated anomalous meridional SST gradient (Fig. 6, right). Then the SST gradients further deepen the anomalous North Pacific low, strengthening the PDO pattern. Therefore, the forced mode is initiated by the volcanoweakened LSTC and the WNP northerly anomalies, leading to the WNP cooling and the reduced downward heat flux, which further leads to the intensified KOE cooling.

Recent studies motivate us to examine AMO's role in the forced mode. Mann et al. (2021) found a 50-70 year 
Fig. 6 Regressed SST $\left({ }^{\circ} \mathrm{C}\right.$, shading) and $925 \mathrm{hPa}$ winds $\left(\mathrm{m} \mathrm{s}^{-1}\right.$, vectors) on the intrinsic mode (IM) index in the Ctrl experiment (left column) and the forced mode (FM) index during the LIA in the Vol experiment (right column). Negative lag indicates the IM/FM index is lagging the anomalous SST and winds and vice versa. Results in the left column are 15-45-year band-pass filtered, while results in the right column are 45-year low-pass filtered. Only the significant results with confidence level exceeding the 90\% (two-tailed Student's $t$-test) are displayed

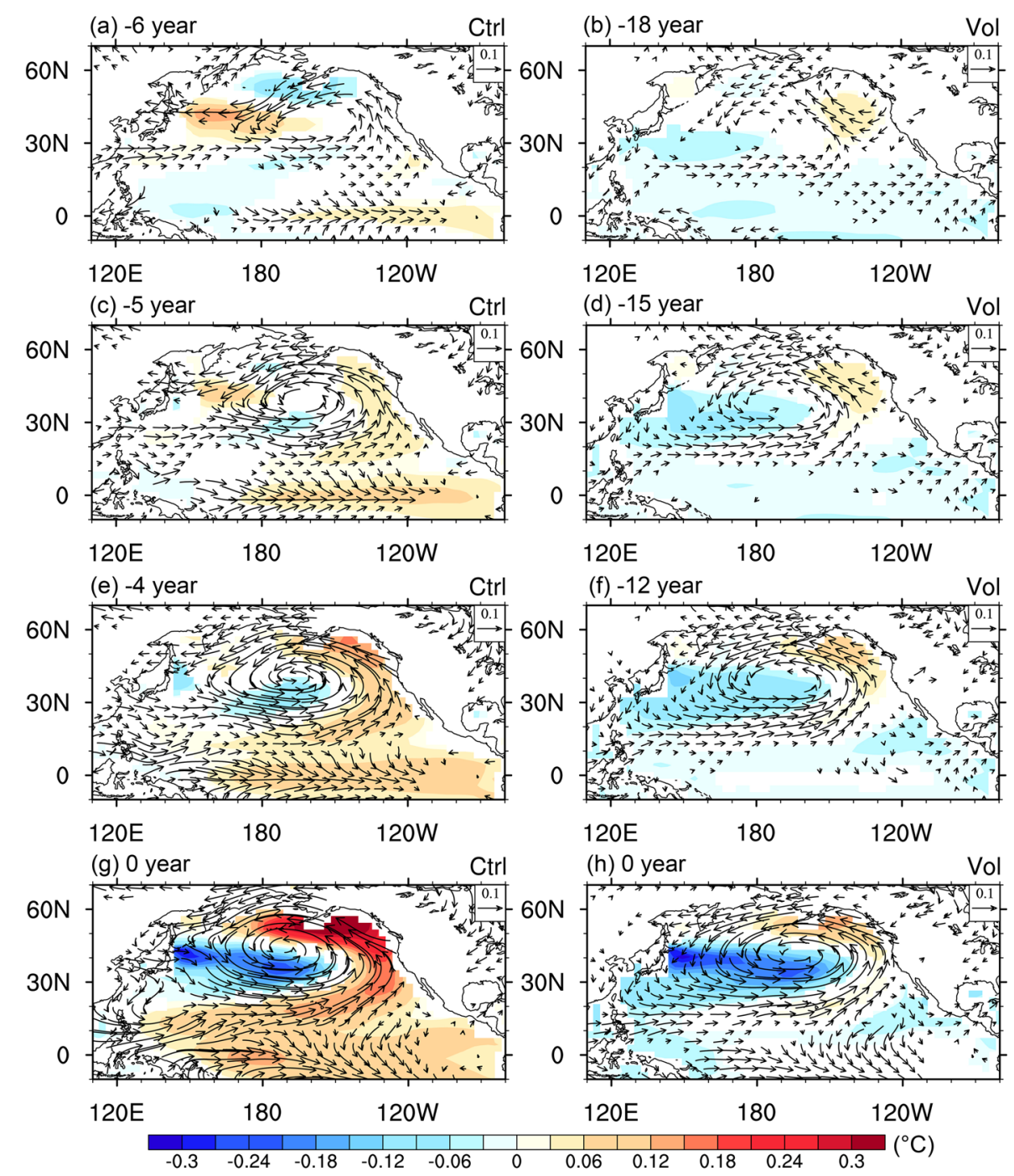

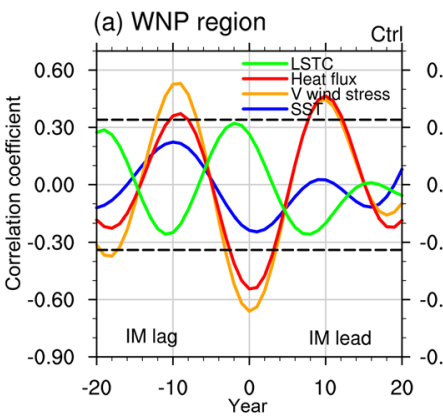

(b) WNP region

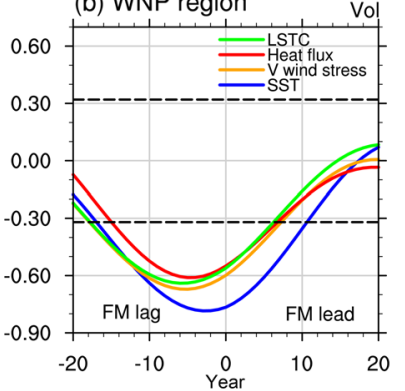

Fig. 7 a Lead-lag correlation coefficient between the intrinsic mode index and SST (blue lines), surface wind stress in v-direction (orange lines) and downward surface heat flux (red lines) over the western North Pacific (WNP, $20^{\circ} \mathrm{N}-35^{\circ} \mathrm{N}, 120^{\circ} \mathrm{E}-150^{\circ} \mathrm{E}$ ), and land-sea thermal contrast (LSTC, green lines) in the Ctrl experiment. $\mathbf{b}$ are the same as a, but for the forced mode index during the LIA in the Vol experiment. Negative lag indicates the IM/FM index is lagging and vice versa. Results in a are 15-45-year band-pass filtered, while results in b are 45-year low-pass filtered. The black dashed lines denote significance at the $95 \%$ confidence level ( $r$ test) frequency of the AMO driven by volcanic forcing during the past millennium. Yang et al. (2020) demonstrated with numerical experiments that the AMO plays a crucial role in the multidecadal variability of the Pacific SST, with the AMO leading PDO by $4-8$ year. It is conceivable that the change in volcano-induced AMO variability may affect the Pacific multidecadal variability during the LIA. In this study, we define the AMO index by the departure of the annual mean SST averaged over the North Atlantic $\left(0^{\circ}-60^{\circ} \mathrm{N}\right.$, $\left.75^{\circ} \mathrm{W}-7.5^{\circ} \mathrm{E}\right)$ from the global mean SST at each time interval to reduce the global temperature change caused by volcanic forcing (Ratna et al. 2019). The defined AMO index reflects a volcano-modulated AMO variability. The result indicates that a lower-frequency (50-70 year) periodicity of AMO during the LIA occurs under the volcanic forcing (Fig. 8a), resembling the PDO periodicity change (Fig. 2c). The regression map shows that the AMO cooling tends to lead the KOE cooling and anomalous North Pacific cyclone by 6 year in the Vol experiment (Fig. 8c), similar 

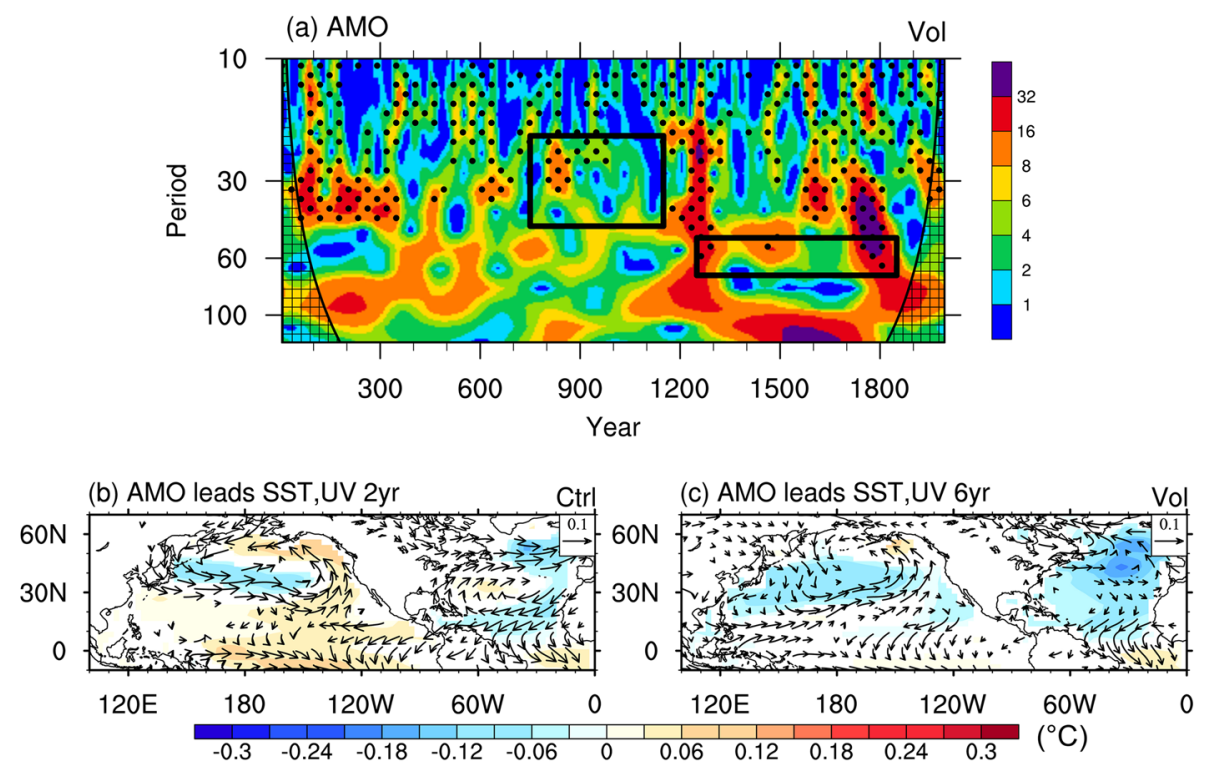

Fig. 8 a Wavelet analysis of the AMO index in the Vol experiment. The black boxes outline the 20-45 year variation during the MCA and 50-70 year variation during the LIA, respectively. The black dots denote the significance at the $90 \%$ confidence level. b, c show the regressed anomalous SST and $925 \mathrm{hPa}$ winds on the normalized AMO index in the Ctrl experiment after 15-45-year band-pass filter-

to the spatial pattern of the forced mode (Fig. 6h). The correlation coefficient between the AMO index and the forced mode index delayed by 6 year during the LIA after a 45 year low-pass filter is about $0.50(p<0.01$, with the effective degrees of freedom around 25). Meanwhile, a recent study also found that the AMO-negative phase can affect the North Pacific subtropical mode water, which further reduces the ocean heat content over the Northwestern Pacific (Wu et al. 2020). It means that the volcanism-influenced multidecadal change in the AMO may contribute to the Pacific 50-70 year variability.

Tropical forcing is an important driver for the PDO's development in previous works (i.e., Alexander 2010). Indeed, in the Ctrl experiment, the development period of intrinsic mode is related to significant warming over the equatorial central-eastern Pacific (Fig. 6, left), suggesting that the ENSO-like SST gradient could play a constructive role. However the anomalous equatorial SST gradient is absent for the forced mode during its development (Fig. 6, right). We also computed the 45 year low-pass filtered zonal equatorial Pacific SST gradient during the LIA, which is defined by the difference between the SSTs over the western Pacific $\left(5^{\circ} \mathrm{S}-5^{\circ} \mathrm{N}, 120^{\circ} \mathrm{E}-150^{\circ} \mathrm{E}\right)$ and the eastern Pacific $\left(5^{\circ} \mathrm{S}-5^{\circ} \mathrm{N}, 150^{\circ} \mathrm{W}-120^{\circ} \mathrm{W}\right)$. There is no significant leadlag correlation between the forced mode and zonal SST gradient (Fig. S6b). Thus, the 60 year forced mode has little to do with the remote tropical SST forcing. The result indicates different origins of the intrinsic and forced modes. ing (b) and in the Vol experiment after 45-year low-pass filtering during the LIA (c), respectively. The labels "lead" in (b) and (c) denote that the AMO index leads the anomalous SST and winds. Only the significant results with a confidence level exceeding the 90\% (twotailed Student's $t$-test) are displayed in (b) and (c)

Previous studies suggested that the bi-decadal PDO mode is mainly influenced by the westward propagation speed of oceanic Rossby waves (Schneider and Miller 2001; Zhang and Delworth 2015). Through investigating the buoyancy frequency over the North Pacific $\left(20^{\circ} \mathrm{N}-60^{\circ} \mathrm{N}\right.$, $140^{\circ} \mathrm{E}-140^{\circ} \mathrm{W}$ ) and the zonally averaged Rossby wave speed in the Vol experiment (Fig. S5), we found no substantial difference between the results in the MCA and LIA. It suggests that the westward propagation speed of oceanic Rossby waves has no apparent contribution to the changes in the amplitude and periodicity of the forced mode during the LIA.

\section{Summary and discussion}

The main findings are summarized as follows:

1. The paleo-assimilation products (LMR) and proxy data suggest that the 20-40 year PDO occurred during both the MCA and LIA, while a salient 50-70 year variance peak emerged during the LIA (Figs. 2a, 3a-d). These findings are reproduced well by the CESM simulations in the all-forcing (AF) experiment, single volcanic forcing ( $\mathrm{Vol})$, and solar irradiance forcing experiments (Fig. 2b-d).

2. The $20-40$ year PDO is an intrinsic mode caused by internal variability (Fig. 3g). In contrast, the 50-70 year 

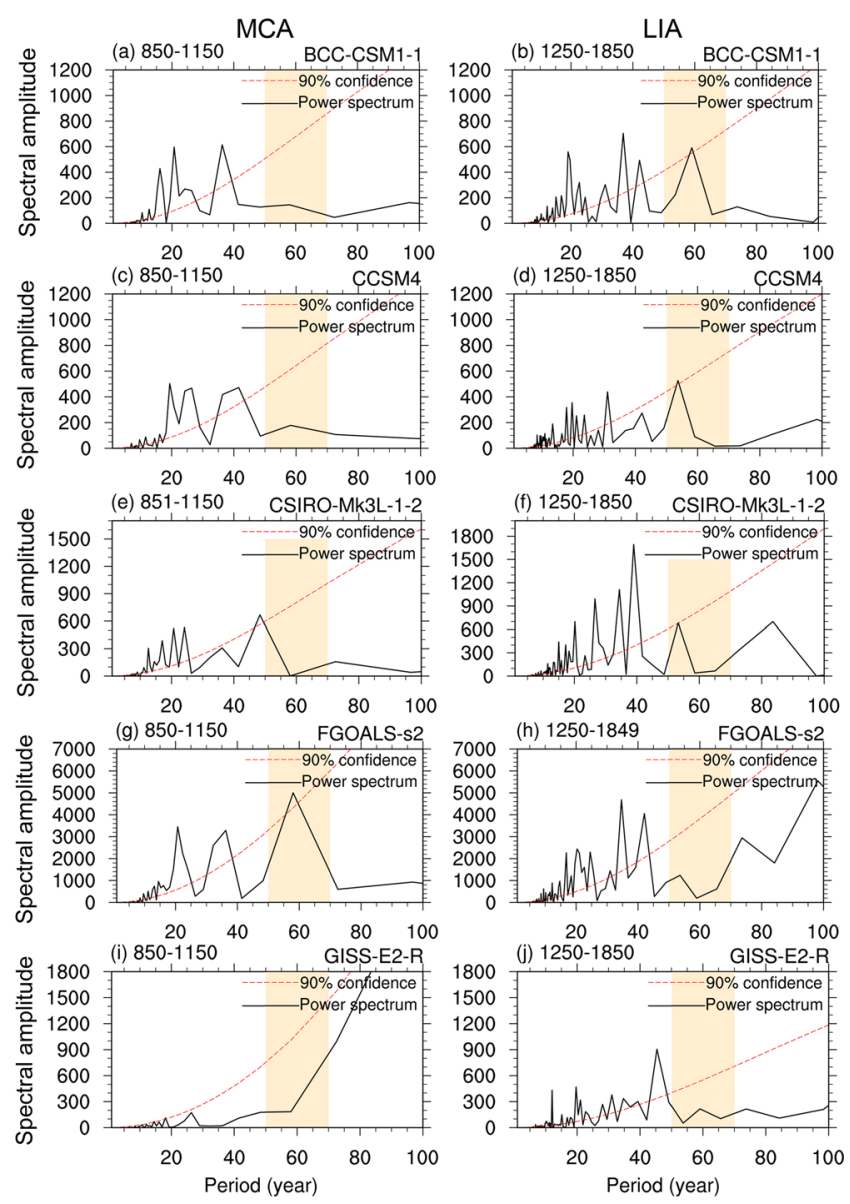

Fig. 9 The power spectrum analysis of the 9-year low-pass filtered PDO index from the PMIP3 (a-r) and PMIP4 (s, t) models during the MCA and LIA. The dashed red line in each panel represents the $90 \%$ confidence level. The orange shadings mark the periodic-

PDO variability during the LIA is a forced mode shaped by volcanic eruptions and solar irradiation. Volcanic forcing plays a more important role in affecting the amplitude of the forced mode (Figs. 4, 5).

3. The intrinsic and forced modes exhibit different development and evolution. The forced mode develops from the western Pacific and unrelated to tropical SST anomalies, while the intrinsic mode develops in tendon with tropical ENSO-like SST anomalies (Fig. 6).

4. The volcanism-induced land-sea thermal contrast may trigger anomalous northerlies over the WNP, leading to the WNP cooling and the reduced downward heat flux. It further weakens the northward transport of warm water in the western boundary and KOE, intensifying the central North Pacific cooling of the forced mode (Fig. 7).

5. A 50-70 year AMO created during the LIA under volcanic forcing may also contribute to the Pacific 50-70 year variability (Fig. 8).
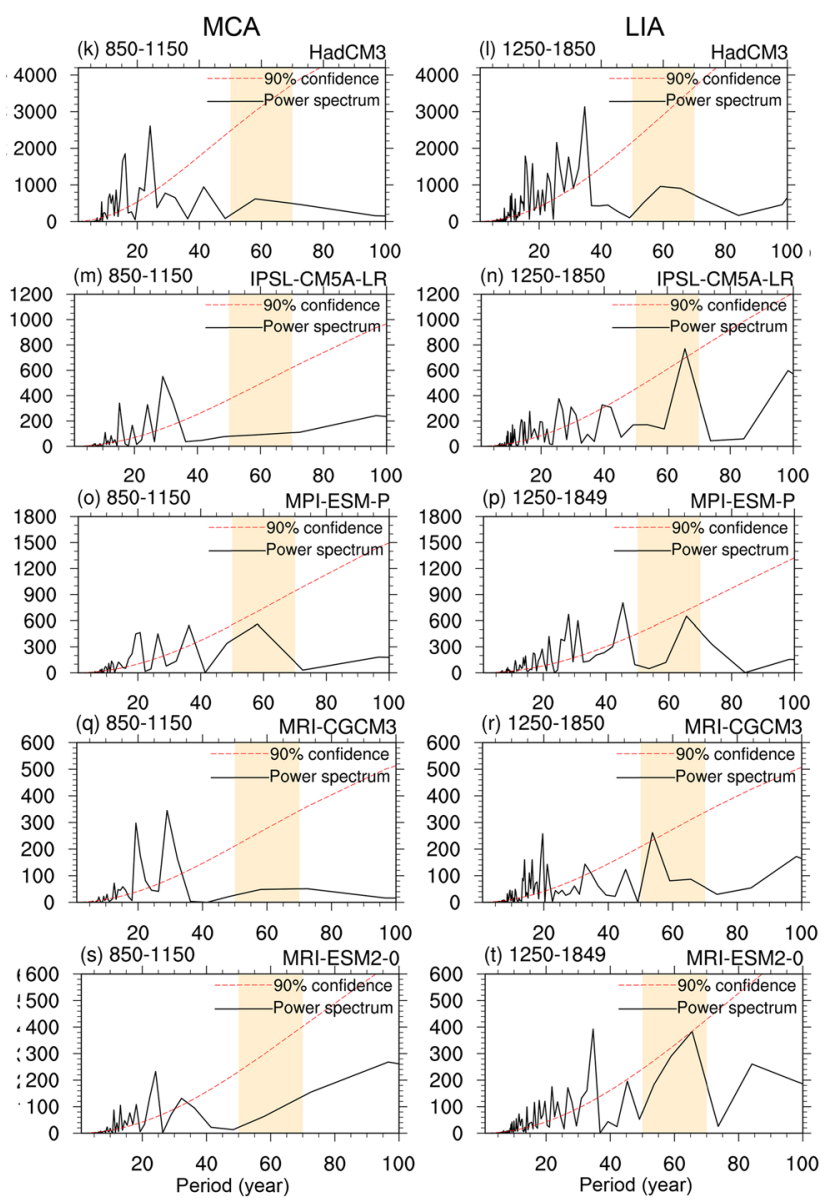

ity of 50-70 year. Six out of ten models show that the significant 50-70 year cycle of the PDO occurs during the LIA while it disappears during the MCA

Under the TSI forcing, the multidecadal variability over the central North Pacific changed the most during the LIA (Figs. 4f, 5c). We found that the decreased zonal equatorial Pacific SST gradient leads the forced mode by $8-9$ years in the TSI experiment (Fig. S6a). Previous studies suggested that the TSI forcing can affect the zonal equatorial Pacific SST gradient through the "bottom-up" mechanism (Meehl and Arblaster 2009). The minimum of solar activity can decrease the zonal equatorial Pacific SST gradient, inducing the deepened Aleutian low through the "atmospheric bridge", which reduces the central North Pacific SST (Alexander et al. 2002). However, the TSI forcing used in this study is reconstructed by Shapiro et al. (2011), which has the largest amplitude compared with other reconstructed TSI and may overestimate TSI's effect on the PDO. Additionally, the TSI forcing shows the significant multidecadal variability during both the MCA and LIA (Fig. S3c, d), but the forced mode only occurs during the LIA in the 
TSI experiment (Fig. 3j, k). These uncertainties need to be solved by ensemble and sensitivity experiments in the future. We further analyzed the results from the PMIP past 1000 simulations (where the TSI forcings' magnitudes are much smaller than our experiments) and found that six out of ten models show an intrinsic mode (20-40 year) during the period of 850-1150 and a forced mode (50-70 year) during the LIA (Fig. 9). So we suggest the volcanic forcing might play a primary role in the emerging $50-70$ year forced mode during the LIA.

In this study, the initial conditions of the Common Era simulations are based on the equilibrium state of control experiment. Zhu et al. (2019) hypothesized that past, current and future multidecadal fluctuations in surface temperature (including the Pacific) may originate from the continuum of climate variability (Huybers and Curry 2006). That is, such variations in the ocean heat content, may be echoes of the past deglaciation, which is called "echo hypothesis" (Zhu et al. 2019). The work of Gebbie and Huybers (2019) suggests that there is thermal disequilibrium in the world's oceans, giving some credence to the echo hypothesis. Thus, assuming that it was a state of equilibrium from the control run has some implications for the attribution of decadal variability, and the initial conditions that grossly approximate the thermal structure of the ocean 1000 or 2000 years ago need to be considered in future.

Arguably, the mechanisms driving PDO change are likely to be complex under different climate conditions. Recent studies found that the periodicity of the PDO is shortening, and the growth rate is slowing down under global warming, leading to a decrease in PDO amplitude (Zhang and Delworth 2016; Geng et al. 2019; Li et al. 2020). We found the opposite characteristics of PDO change during the global cooling period of the LIA. Our findings corroborated the previous results and may shed light on future PDO change. However, one has to bear in mind that the mechanism of PDO's forced mode during the LIA is likely to be different from that under anthropogenic warming. More PDO reconstructions and modeling works covering the past two millennia are needed to verify this study' results and to better understand how the PDO is likely to change in a warming climate.

Supplementary Information The online version contains supplementary material available at https://doi.org/10.1007/s00382-021-06127-7.

Acknowledgements We thank the HadiSST, ERSST, LMR, and PMIP3/4 for providing the observations, assimilation, and modeling data. We thank two anonymous reviewers for their valuable comments and suggestions. Our study is supported by the National Natural Science Foundation of China (42130604, 42105044, 41971108, 42111530182, 91437218), and Swedish STINT (CH2019-8377), and Priority Academic Program Development of Jiangsu Higher Education Institutions (164320H116).
Open Access This article is licensed under a Creative Commons Attribution 4.0 International License, which permits use, sharing, adaptation, distribution and reproduction in any medium or format, as long as you give appropriate credit to the original author(s) and the source, provide a link to the Creative Commons licence, and indicate if changes were made. The images or other third party material in this article are included in the article's Creative Commons licence, unless indicated otherwise in a credit line to the material. If material is not included in the article's Creative Commons licence and your intended use is not permitted by statutory regulation or exceeds the permitted use, you will need to obtain permission directly from the copyright holder. To view a copy of this licence, visit http://creativecommons.org/licenses/by/4.0/.

\section{References}

Alexander MA (1992) Midlatitude atmosphere-ocean interaction during El Niño. Part I: the North Pacific Ocean. J Clim 5:944958. https://doi.org/10.1175/1520-0442(1992)005\%3c0944: MAIDEN\%3e2.0.CO;2

Alexander MA (2010) Extratropical air-sea interaction, SST variability and the Pacific Decadal Oscillation (PDO). In: Sun D, Bryan F (eds) Climate dynamics: why does climate vary. Washington D.C: AGU Monograph \#189, pp 123-48

Alexander MA, Blade I, Newman M et al (2002) The Atmospheric Bridge: the Influence of ENSO teleconnections on air-sea interaction over the global oceans. J Clim 15:2205-2231

Biondi F, Gershunov A, Cayan DR (2001) North Pacific decadal climate variability since 1661. J Clim 14:5-10. https://doi.org/10. 1175/1520-0442(2001)014\%3c0005:NPDCVS\%3e2.0.CO;2

Bretherton CS, Widmann M, Dymnikov VP, Wallace JM, Zladé I (1999) The effective number of spatial degrees of freedom of a time-varying field. J Clim 12:1990-2009. https://doi.org/10. 1175/1520-0442(1999)012\%3c1990:TENOSD\%3e2.0.CO;2

D'Arrigo R, Wilson R (2006) On the Asian expression of the PDO. Int J Climatol 26:1607-1617. https://doi.org/10.1002/joc.1326

Deser C, Phillips A, Hurrell JW (2004) Pacific interdecadal climate variability: linkages between the Tropics and North Pacific during boreal winter since 1900. J Clim 17:3109-3124

Deser C, Phillips AS, Tomas R (2012) ENSO and Pacific decadal variability in the Community Climate System Model version 4. J Clim 25:2622-2651. https://doi.org/10.1175/ JCLI-D-11-00301.1

Di Lorenzo E, Mantua N (2016) Multi-year persistence of the 2014/15 North Pacific marine heatwave. Nat Clim Change 6:1042-1047. https://doi.org/10.1038/nclimate308

Fang K, Chen D, Ilvonen L et al (2019) Oceanic and atmospheric modes in the Pacific and Atlantic Oceans since the Little Ice Age (LIA): towards a synthesis. Quat Sci Rev 215:293-307. https://doi.org/10.1016/j.quascirev.2019.05.014

Gao C, Robock A, Ammann C (2008) Volcanic forcing of climate over the past 1500 years: an improved ice core-based index for climate models. J Geophys Res Atmos 113:D23111. https://doi. org/10.1016/10.1029/2008jd010239

Gebbie G, Huybers P (2019) The little ice age and 20th-century deep pacific cooling. Science 363(6422):70. https://doi.org/10.1126/ science.aar8413

Geng T, Yang Y, Wu L (2019) On the mechanisms of Pacific decadal oscillation modulation in a warming climate. J Clim 32:14431459. https://doi.org/10.1175/JCLI-D-18-0337.1

Huang B, Thorne PW, Banzon V et al (2017) Extended reconstructed sea surface temperature, version 5 (ERSSTv5): upgrades, validations, and intercomparisons. J Clim 30:8179-8205. https://doi. org/10.1175/JCLI-D-16-0836.1 
Hurrell J, Holland MM, Gent P et al (2013) The Community Earth System Model: a framework for collaborative research. Bull Am Meteorol Soc 94:1339-1360. https://doi.org/10.1175/ BAMS-D-12-00121.1

Huybers P, Curry W (2006) Links between annual, milankovitch and continuum temperature variability. Nature 441(7091):329-332

IPCC (2013) Climate Change 2013: The Physical Science Basis. Contribution of Working Group I to the Fifth Assessment Report of the Intergovernmental Panel on Climate Change [Stocker, T.F., D. Qin, G.-K. Plattner, M. Tignor, S.K. Allen, J. Boschung, A. Nauels, Y. Xia, V. Bex and P.M. Midgley (eds.)]. Cambridge University Press, Cambridge

Jin C, Liu J, Wang B, Yan M, Ning L (2019) Decadal variations of the East Asian summer monsoon forced by 11-year insolation cycle. J Clim 32:2735-2745. https://doi.org/10.1175/JCLI-D-18-0288.1

Jungclaus JH, Bard E, Baroni M et al (2017) The PMIP4 contribution to CMIP6-Part 3: the last millennium, scientific objective, and experimental design for the PMIP4 past 1000 simulations. Geosci Model Dev 10(11):4005-4033

Kaplan JO, Krumhardt KM, Ellis EC et al (2010) Holocene carbon emissions as a result of anthropogenic land cover change. Holocene 21:775-791. https://doi.org/10.1177/0959683610386983

Kwon Y-O, Deser C (2007) North Pacific decadal variability in the Community Climate System Model version 2. J Clim 20:24162433. https://doi.org/10.1175/JCLI4103.1

Latif M, Barnett TP (1994) Causes of decadal climate variability over the North Pacific and North America. Science 266:634-637. https://doi.org/10.1126/science.266.5185.634

Li S, Wu L, Yang Y et al (2020) The pacific Decadal Oscillation less predictable under greenhouse warming. Nat Clim Change 10:30 34. https://doi.org/10.1038/s41558-019-0663-x

Liguori G, Di Lorenzo E (2018) Meridional modes and increasing Pacific decadal variability under anthropogenic forcing. Geophys Res Lett 45:983-991. https://doi.org/10.1002/2017GL076548

Liu Z, Di Lorenzo E (2018) Mechanisms and predictability of Pacific decadal variability. Curr Clim Change Rep 4:128-144. https://doi. org/10.1007/s40641-018-0090-5

Liu F, Chai J, Wang B, Liu J, Zhang X, Wang Z (2016) Global monsoon precipitation responses to large volcanic eruptions. Sci Rep 6:24331. https://doi.org/10.1038/srep24331

Liu B, Wang B, Liu J et al (2020) Global and polar region temperature change induced by single mega volcanic eruption based on Community Earth System Model simulation. Geophys Res Lett 47:e2020GL089416. https://doi.org/10.1029/2020GL089416

MacDonald GM, Case RA (2005) Variations in the Pacific Decadal Oscillation over the past millennium. Geophys Res Lett 32:L08703. https://doi.org/10.1029/2005GL022478

MacFarling C, Etheridge D, Trudinger CM et al (2006) Law Dome $\mathrm{CO} 2, \mathrm{CH} 4$ and $\mathrm{N} 2 \mathrm{O}$ ice core records extended to 2000 years BP. Geophys Res Lett 33:L14810. https://doi.org/10.1029/2006G L026152

Man W, Zhou T, Jungclaus JH (2014) Effects of large volcanic eruptions on global summer climate and east Asian monsoon changes during the last millennium: analysis of MPI-ESM simulations. J Clim 27:7394-7409

Mann ME, Steinman BA, Brouillette DJ, Miller SK (2021) Multidecadal climate oscillations during the past millennium driven by volcanic forcing. Science 371:1014-1019

Mantua NJ, Hare SR, Zhang Y, Wallace JM, Francis RC (1997) A Pacific interdecadal climate oscillation with impacts on salmon production. Bull Am Meteorol Soc 78:1069-1079. https://doi.org/ 10.1175/1520-0477(1997)078,1069:APICOW.2.0.CO;2

Meehl GA, Arblaster JM (2009) A lagged warm event-like response to peaks in solar forcing in the Pacific region. J Clim 22:3647-3660
Newman M, Alexander MA, Ault TR et al (2016) The Pacific decadal oscillation, revisited. J Clim 29:4399-4427. https://doi.org/10. 1175/JCLI-D-15-0508.1

Otto-Bliesner BL, Brady EC, Fasullo JT et al (2016) Climate variability and change since $850 \mathrm{C} \mathrm{E}$ : an Ensemble Approach with the Community Earth System Model (CESM). Bull Am Meteorol Soc. https://doi.org/10.1175/BAMS-D-14-00233.1

Ratna SB, Osborn TJ, Joshi M, Yang B, Wang J (2019) Identifying teleconnections and multidecadal variability of East Asian surface temperature during the last millennium in CMIP5 simulations. Clim past 15:1825-1844. https://doi.org/10.5194/ cp-15-1825-2019

Rayner NA, Parker D, Horton EB et al (2003) Global analyses of sea surface temperature, sea ice, and night marine air temperature since the late nineteenth century. J Geophys Res Atmos 108:447. https://doi.org/10.1029/2002JD002670

Schmidt GA, Jungclaus JH, Ammann CM et al (2011) Climate forcing reconstructions for use in PMIP simulations of the last millennium (v1.0). Geosci Model Dev 4:33-45. https://doi.org/10.5194/ gmd-4-33-2011

Schneider N, Miller AJ (2001) Predicting western North Pacific Ocean climate. J Clim 14:3997-4002. https://doi.org/10.1175/15200442(2001)014\%3c3997:PWNPOC\%3e2.0.CO;2

Shapiro AI, Schmutz W, Rozanov E, Schoell M, Nyeki S (2011) A new approach to the long-term reconstruction of the solar irradiance leads to large historical solar forcing. Astron Astrophys 529:1-8. https://doi.org/10.1051/0004-6361/201016173

Sigl M, Winstrup M, Mcconnell JR et al (2015) Timing and climate forcing of volcanic eruptions for the past 2,500 years. Nature 523:543-549. https://doi.org/10.1038/nature14565

Singh HK, Hakim GJ, Tardif R, Emile-Geay J, Noone DC (2018) Insights into Atlantic multidecadal variability using the Last Millennium Reanalysis framework. Clim past 14:157-174

Sun W, Liu J, Wang Z (2017) Simulation of centennial-scale drought events over eastern China during the past 1500 years. J Meteorol Res 31:17-27. https://doi.org/10.1007/s13351-017-6090-x

Sun W, Wang B, Liu J et al (2019a) How northern high-latitude volcanic eruptions in different seasons affect ENSO. J Clim 32:32453262. https://doi.org/10.1175/JCLI-D-18-0290.1

Sun W, Liu J, Wang B et al (2019b) A "La Niña-like" state occurring in the second year after large tropical volcanic eruptions during the past 1500 years. Clim Dyn 52:7495-7509. https://doi.org/10. 1007/s00382-018-4163-x

Taguchi B, Xie SP, Schneider N, Nonaka M, Sasaki H, Sasai Y (2007) Decadal variability of the Kuroshio extension: observations and an eddy-resolving model hindcast. J Clim 20:2357-2377. https:// doi.org/10.1175/JCLI4142.1

Tardif R, Hakim GJ, Perkins W et al (2019) Last Millennium Reanalysis with an expanded proxy database and seasonal proxy modeling. Clim past 15:1251-1273. https://doi.org/10.5194/ cp-15-1251-2019

Tejedor E, Steiger N, Smerdon JE, Serrano-Notivoli R, Vuille M (2021) Global temperature responses to large tropical volcanic eruptions in paleo data assimilation products and climate model simulations over the last millennium. Paleoceanogr Paleocl 36:e2020PA004128. https://doi.org/10.1029/2020PA004128

Toohey M, Sigl M (2017) Volcanic stratospheric sulfur injections and aerosol optical depth from 500BCE to 1900CE. Earth Syst Sci Data 9:809-831

Vimont DJ, Battisti S, Hirst AC (2001) Footprinting: a seasonal connection between the tropics and mid-latitudes. Geophys Res Lett 28:3923-3926. https://doi.org/10.1029/2001GL013435

Wang T, Ottera OH, Gao Y, Wang H (2012) The response of the North Pacific Decadal Variability to strong tropical volcanic eruptions. Clim Dyn 39:2917-2936. https://doi.org/10.1007/ s00382-012-1373-5 
Wang Z, Li Y, Liu B, Liu J (2015) Global climate internal variability in a 2000-year control simulation with Community Earth System Model (CESM). Chin Geogr Sci 25:263-273. https://doi.org/10. 1007/s11769-015-0754-1

Wang Q, Yan M, Liu J, Ning L (2021) Impacts of land use/cover change on spatial patterns of summer precipitation at decadal scale over eastern China. Int J Climatol 41:1939-1951. https:// doi.org/10.1002/joc.6939

Wu B, Lin X, Yu L (2020) North pacific subtropical mode water is controlled by the Atlantic Multidecadal variability. Nat Clim Change 10:238-243

Yan M, Liu J, Wang Z (2017) Global climate responses to land use and land cover changes over the past two millennia. Atmosphere 8:64. https://doi.org/10.3390/atmos8040064

Yang Y-M, An S-I, Wang B, Park JH (2020) A global-scale multidecadal variability driven by Atlantic multidecadal oscillation. Natl Sci Rev 7:1190-1197. https://doi.org/10.1093/nsr/nwz216

Zhang L, Delworth TL (2015) Analysis of the characteristics and mechanisms of the Pacific decadal oscillation in a suite of coupled models from the geophysical fluid dynamics laboratory. J Clim 28:7678-7701. https://doi.org/10.1175/JCLI-D-14-00647.1

Zhang L, Delworth TL (2016) Simulated response of the Pacific decadal oscillation to climatic change. J Clim 29:5999-6018. https:// doi.org/10.1175/JCLI-D-15-0690.1
Zhang Y, Xie SP, Kosaka Y, Yang JC (2018) Pacific decadal oscillation: tropical pacific forcing versus internal variability. J Clim 31:8265-8279. https://doi.org/10.1175/JCLI-D-18-0164.1

Zhong Y, Liu Z (2009) On the mechanism of Pacific multidecadal climate variability in CCSM3: the role of the subpolar North Pacific Ocean. J Phys Oceanogr 39:2052-2076

Zhong Y, Liu Z, Jacob R (2008) Origin of Pacific multidecadal variability in community climate system model, version 3 (CCSM3): a combined statistical and dynamical assessment. J Clim 21:114-133

Zhu F, Emile-Geay J, McKay NP et al (2019) Climate models can correctly simulate the continuum of global-average temperature variability. Proc Natl Acad Sci 116(18):8728. https://doi.org/10. 1073/pnas. 1809959116

Publisher's Note Springer Nature remains neutral with regard to jurisdictional claims in published maps and institutional affiliations. 